Original article

\title{
Experimental study of synthetic polymeric materials as a basis for developing advanced carrier matrices for cultivating limbal stem cells
}

\author{
Vadim V. Karpovich ${ }^{1}$, Alexey N. Kulikov ${ }^{1}$, Sergey V. Churashov' ${ }^{1}$, Valery F. Chernysh ${ }^{1}$, \\ Stepan G. Grigoriev ${ }^{1}$, Miralda I. Blinova ${ }^{2}$, Yulia A. Nashchekina ${ }^{2}$, Olga I. Aleksandrova ${ }^{2}$, \\ Yulia I. Khorolskaya ${ }^{2}$, Pavel O. Nikonov' ${ }^{2}$, Ekaterina S. Tsobkallo3, Olga A. Moskalyuk3, \\ Alexander S. Melnikov ${ }^{4}$, Pavel Yu. Serdobintsev ${ }^{4}$, Tatiana V. Mashel ${ }^{4}$, Galina A. Pisugina ${ }^{5}$, \\ Daria A. Perepletchikova ${ }^{4}$, Dmitry A. Khoroshikh ${ }^{1}$
}

${ }^{1}$ S.M. Kirov Military Medical Academy, St. Petersburg, Russia ${ }^{2}$ Institute of Cytology, Russian Academy of Sciences, St. Petersburg, Russia ${ }^{3}$ Saint Petersburg State University of Industrial Technology and Design, St. Petersburg, Russia 4 Peter the Great St. Petersburg Polytechnic University, St. Petersburg, Russia 5 Saint Petersburg State University, St. Petersburg, Russia

Received 15 May 2019, Accepted 20 November 2020

Original Text (C) Karpovich V.V., Kulikov A.N., Churashov S.V., Chernysh V.F., Grigoriev S.G., Blinova M.I., Nashchekina Yu.A., Aleksandrova O.I., Khorolskaya Yu.I., Nikonov P.O., Tsobkallo E.S., Moskalyuk O.A., Melnikov A.S., Serdobintsev P.Yu., Mashel' T.V., Pisugina G.A., Perepletchikova D.A., Khoroshikh D.A., 2019, published in Saratov Journal of Medical Scientific Research $2019 ; 15$ (2): 495-501. (C) 2020, Karpovich V.V., Kulikov A.N., Churashov S.V., Chernysh V.F., Grigoriev S.G., Blinova M.I., Nashchekina Yu.A., Aleksandrova O.I., Khorolskaya Yu.I., Nikonov P.O., Tsobkallo E.S., Moskalyuk O.A., Melnikov A.S., Serdobintsev P.Yu., Mashel' T.V.,

Pisugina G.A.,Perepletchikova D.A., Khoroshikh D.A.

(C) 2020, Saratov Medical Journal

\begin{abstract}
:
Objective: to conduct an experimental study on the properties of three different types of synthetic polyester matrices, to carry out their comparative assessment, and to identify the optimal carrier for the cultivation and transplantation of limbal stem cells while eliminating limbal insufficiency.

Materials and methods. Transparency, mechanical properties (strength, relative elongation at break, and elastic modulus), biocompatibility with corneal cell cultures were assessed, and duration of matrix biodegradation in vivo were studied.

Results. In the course of our study, the optical and mechanical properties of matrices, made of polylactide-glycolide (PLG), polylactide-caprolactone (PLC) and poly-E-caprolactone (PCL), were studied. It has been experimentally shown that limbal stem cells of humans and rabbits, as well as human corneal epithelial cells, adhered to the surface of all types of the studied matrices. During the cultivation process, they retained the typical structure of the actin cytoskeleton, along with the ability to proliferate and migrate. Differences in the interaction of different cell cultures with different types of carriers were revealed. The biodegradation time of $5 \mu \mathrm{m}$ thick PLC matrices was about 30 days.

Conclusion. Our results obtained implied the possibility of using $5 \mu \mathrm{m}$ thick PLC matrices as a carrier for cultured limbal stem cells.
\end{abstract}

Keywords: synthetic polymers, corneal transparency, mechanical properties, biocompatibility, limbal stem cells.

Cite as Karpovich VV, Kulikov AN, Churashov SV, et al. Experimental study of synthetic polymeric materials as a basis for developing advanced carrier matrices for cultivating limbal stem cells. Saratov Medical Journal 2020; 1(2): e0203.

Correspondence to Vadim V. Karpovich. Тел.: + 7(981) 902 0303; E-mail: yalovelife@mail.ru

\section{Introduction}

Diseases and injuries of the cornea account for about $25 \%$ of all ocular pathology. According to the World Health Organization, in the structure of ocular morbidity, such pathological conditions rank fourth (5\%), second only to cataracts (47\%), glaucoma (12\%) and age-related macular degeneration $(9 \%)[1,2]$. The most common of them are ulcers and corneal opacity after an infectious pathology, trauma or burns, as well as xerophthalmia in childhood [3].

There were 224 thousand blind and visually impaired people in the Russian Federation, registered by the Russian National Society of Visually Impaired in 2003, and the level of blindness and poor visual acuity was 15.2 cases per 10 thousand of the population [4]. Corneal pathology accounted for $10-50 \%$ of these statistics $[5,6]$.

Currently, the core method of surgical treatment of such corneal pathology is penetrating keratoplasty (cornea transplant) $[7,8]$. However, performing kertoplasty in the presence of total vascular leukoma is almost always doomed to failure due to its inevitable recurrence $[7,9]$.

One of primary causes of vascular corneal opacity is limbal stem cell (LSC) dysfunction, clinically manifesting itself as a condition called limbal insufficiency [9, 10]. Currently, the possibility of transplantation of in vitro 
cultured LSCs into the cornea is being investigated as one of the ways to eliminate limbal insufficiency [11]. The most common carrier for LSC cultivation in the world is the amniotic membrane (AM) [11, 12]. At the same time, the shortage of this material, the presence of certain difficulties in the procurement, conservation and use of $\mathrm{AM}$ for the indicated purposes necessitate the search for new types of carrier matrices made from biological or synthetic materials.

Objective: to conduct an experimental study on the properties of three different types of synthetic polyester matrices, to carry out their comparative assessment, and to identify the optimal carrier for the cultivation and transplantation of LSCs while eliminating limbal insufficiency.

\section{Materials and methods}

For preparation of matrices, we used poly-L-lactideglycolide (85/15) (PLG) ( $\mathrm{h}=3.1 \mathrm{dl} / \mathrm{g}$, Purac), poly-L-lactidecaprolactone (85/15) (PLC) $(\mathrm{h}=1.6 \mathrm{dl} / \mathrm{g}$, Purac), poly-Ecaprolactone) (PCL) (Mn 80,000, Sigma). The PLG and PLC materials were of the medical grade purity. The PCL material had no purity grade. The polymers were dissolved in trichloromethane (Reaktiv, Russia) to a final concentration of $2 \mathrm{mg} / \mathrm{ml}$ and applied to glass slides for microscope. After evaporation of the solvent in the air, the matrices were dried at $37^{\circ} \mathrm{C}$ until the solvent was completely removed. The thickness of the specimens of each synthetic matrix under study was $5,10,15$, and $30 \mu \mathrm{m}$.

To study the transparency of synthetic matrices, the amount of diffuse scattering of light, when passing through the test material, was determined. To determine diffuse light scattering in the matrices, a DH-HN150 helium-neon laser (Beijing, China) with a wavelength of $632.8 \mathrm{~nm}$, a BC106N camera beam profiler (Thorlabs, USA), and lenses with focal lengths of $50 \mathrm{~mm}$ and $75 \mathrm{~mm}$ were used. The amount of light scattering, when passing through the matrix, was calculated from the ratio $l=a / b$, where $a$ is the intensity of light transmitted through the object, inside the solid angle of $2,5^{\circ}$ $\left( \pm 1,25^{\circ}\right) ; \mathrm{b}$ is the total intensity of the light transmitted through the object.

We investigated matrices with different thickness values: $5,10,15$ and $30 \mu \mathrm{m}$. For each matrix, the determination of the amount of diffuse scattering of light, when passing through the test material, was performed at five different points. As a control, a study of quartz glass (KU-1 quartz optical glass) was carried out. The results were processed using the Origin and Fiji software.

The study of mechanical properties of synthetic matrices and $\mathrm{AM}$ was carried out on the universal testing instrument INSTRON 1122 (Instron, USA) in the uniaxial tension mode. The test speed was $10 \mathrm{~mm} / \mathrm{min}$, and thickness of investigated matrices was 5, 10 and $15 \mu \mathrm{m}$. During the tests, tensile test diagrams of materials were recorded - i.e., dependences $\sigma(\varepsilon)$, on the basis of which the following values were determined: strength ( $\sigma \mathrm{p}, \mathrm{MPa})$; relative elongation at break ( $\mathrm{pp}, \%)$, which characterizes the elasticity of the material; and elastic modulus (E, MPa).

To assess the biocompatibility of matrices made of PLG, PLC and PCL, we used an immortalized human corneal epithelium cells - HCE, as well as primary cultures of human and rabbit LSCs. LSCs were isolated, using the method of F. Sefat et al. [13], at the Institute of Cytology of the Russian Academy of Sciences (St. Petersburg) from fragments of the limbus of human cadaver eyes and whole enucleated eyes of healthy rabbits of chinchilla breed.

All cell types were cultured at $37^{\circ} \mathrm{C}$ in a $\mathrm{CO} 2$ incubator in an atmosphere of $5 \% \mathrm{CO}$. Human and rabbit LSCs were cultured in a DMEM/F12 nutrient medium (Gibco, USA), containing 10\% fetal bovine serum (FBS) (Hy Clone, USA) and $1 \%$ Pen Strep antibiotic solution (Gibco, USA). HCE cells were cultured in Keratinocyte-SFM nutrient medium (Gibco, USA), containing 10\% FBS (Hy Clone, USA) and 1\% Pen Strep antibiotic solution (Gibco, USA). Human and rabbit LSCs were seeded on the surface of the matrices at a concentration of $2 \times 104$ cells/cm2, while HCE cells were seeded at a concentration of $5 \times 104$ cells $/ \mathrm{cm} 2$. Cells were counted using TC-20 equipment from Bio-Rad (USA). Cells cultured under standard conditions without polymer synthetic matrices were used as a control. Three series of independent experiments were carried out with subsequent assessment of the results, obtained using the following methods.

The viability and the ability of cells to adhere was assessed by their morphology via phase-contrast microscopy, using an inverted Nikon Eclipse TS10o microscope. The method of intravital observation under an inverted microscope with photography made it possible to visually assess the morphological state of cells during their cultivation under experimental conditions, and to compare it with the control variant.

Proliferative activity was assessed by the colorimetric test with gentian violet. The cells were seeded on the surface of the matrices and cultured under standard conditions for three days. After the expiration of the cultivation period, the cells on the surface of the matrices, or at the bottom of the culture flask, were fixed with $70 \%$ ethanol solution and stained with $0.2 \%$ gentian violet solution for 10 minutes, followed by washing with distilled water. The dye was extracted with $7 \%$ acetic acid solution. The optical density of the resulting solutions was measured using a Fluorofot Charity analyzer (Russia).

The analysis of the organization of the actin cytoskeleton in the cells spread on the matrices was carried out using $\mathrm{ZOE}^{\mathrm{TM}}$ fluorescent cell imager (Bio-Rad, USA). To visualize actin microfilaments, histochemical staining with rhodaminephalloidin (Invitrogen, USA) of cell culture compositions and matrices, fixed in a $4 \%$ paraformaldehyde solution, was performed. Prior to staining, cells were permeabilized, using $0.1 \%$ Triton $^{\mathrm{TM}} \mathrm{X} 100$ solution. The preparations were embedded in a medium, containing a fluorescent dye 4', 6diamidino-2-phenylindole (DAPI) from Santa Cruz Biotechnology (USA).

The study of the biodegradation duration (in days) of matrices from PLG, PLC, and PCL was performed on 18 rabbits (36 eyes). In group I ( 6 rabbits, 12 eyes), PLG matrices of various thickness values $(5,10$ and $15 \mu \mathrm{m})$ were sutured onto the surface of the cornea: 4 eyes for each thickness value. In groups II and III ( 6 rabbits and 12 eyes in each) there were similar matrices from PLC and PCL. Conservative treatment was carried out as instillation of dexa-gentamicin 3 times a day (up to 21 days). The observation period was $3,10,21$ and 30 days. In each study group, eye biomicroscopy was performed using a Haag-Streit BD90o slit lamp (Switzerland) with photographing the process of biodegradation of matrices in dynamics. The work with the animals was conducted in accordance with the requirements of regulatory and guiding documents (1964 
Declaration of Helsinki with 1975 and 1983 amendments). For implementation of the experiment, permission was obtained from the Ethics Committee at S.M. Kirov Military Medical Academy (protocol No. 215 of November 5, 2018).

The statistical significance of the differences between the studied normally distributed parameters in the experimental groups was assessed using analysis of variance (ANOVA) and constructing 95\% confidence intervals on its basis. The assessment of statistical significance of the differences in parameters, subjected to a distribution other than normal, was conducted using a nonparametric alternative to one-way analysis of variance - the Kruskal-Wallis median test.

\section{Results}

According to the results of our study, the transparency of PLG and PLC matrices of various thicknesses approached 100\%; however, taking into account the error of the research method, it was at least $98-99 \%$. There were no statistically significant differences in the transparency of matrices from PLG and PLC compared to the control ( $\mathrm{p}>0.05)$ (Figure 1).

In the course of studying PCL matrices, it was discovered that their transparency declined significantly with thickness ( $p<0.001$ ), except for the matrices with a thickness of 10 and $15 \mu \mathrm{m}$, where no significant differences were found ( $\mathrm{p}>0.05)$ (Figure 1). For PCL matrices with a thickness of $5,10,15$, and $30 \mu \mathrm{m}$, the transparency indices were $80 \pm 7,43 \pm 5,41 \pm 5$, and $19 \pm 3$ (\%), respectively.

The results of studying the mechanical properties of matrices made of PLG, PLC and PCL of various thicknesses, as well as AM, are presented in the Table.

During the analysis of the obtained data, it was noted that PLG matrices had a sufficiently high strength (up to $51 \pm 4$ $\mathrm{MPa}$ at a thickness of $15 \mu \mathrm{m}$ ), but low elasticity (up to $3.6 \pm 1 \%$ relative elongation at break at a thickness of $15 \mu \mathrm{m}$ ) and excessively high elastic modulus $(2578 \pm 330 \mathrm{MPa}$ at $15 \mu \mathrm{m}$ thickness).

PLC matrices had lower strength (up to $33 \pm 5 \mathrm{MPa}$ at 15 $\mu \mathrm{m}$ thickness) than PLG matrices, but higher elasticity (up to $4.7 \pm 0.8 \%$ relative elongation at break at $15 \mu \mathrm{m}$ thickness) and low elastic modulus $(2186 \pm 575 \mathrm{MPa}$ with a thickness of 15 $\mu \mathrm{m})$.

PCL matrices had lower strength values (up to $14 \pm 1 \mathrm{MPa}$ at $15 \mu \mathrm{m}$ thickness), but higher elasticity (up to $71 \pm 38 \%$ relative elongation at break at $15 \mu \mathrm{m}$ thickness) and lower elastic modulus values ( $349 \pm 40 \mathrm{MPa}$ at $15 \mu \mathrm{m}$ thickness) in comparison with matrices made of PLC and PLG.

$\mathrm{AM}$ had the lowest strength values $(0.8 \pm 0.2 \mathrm{MPa})$ and elastic modulus $(0.19 \pm 0.07 \mathrm{MPa})$ of all materials under study, but rather high values of relative elongation at break $(50 \pm 11 \%)$.

The results of the statistical analysis of the data are presented in Figures 2-4.

In vitro experiments have shown that human and rabbit LSCs, as well as HCE cells, adhere to the surface of all types of synthetic polymer matrices, and during cultivation retain the typical structure of the actin cytoskeleton, along with the ability to proliferate and migrate. However, differences were revealed in the interaction of different cell cultures with different types of matrices.

The results of in vivo observation of the morphological state of LSC (human and rabbit) and HCE cells during their

cultivation on synthetic polyester matrices of PLG, PLC, and PCL are shown in Figure 5.

LSC and HCE cells in the control variant are well spread, have a typical morphology, and on the 2nd day of cultivation, they form a subconfluent monolayer (Figure 5: $A, E, I$ ). The morphology of rabbit LSCs, cultured on all studied types of matrices, did not differ from the control, but the cell density was somewhat lower. Human LSC and HCE, upon cultivation on matrices of PLC and PCL, did not form a subconfluent monolayer on the 2nd day and were grouped at different regions of the matrices. LSCs and HCE were evenly distributed over the surface of PLG matrices, but their density was somewhat lower than in the control.

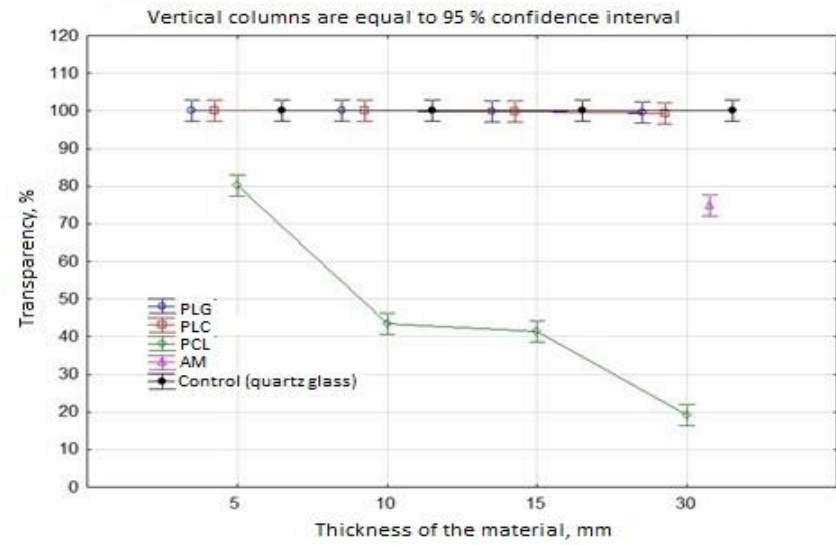

Figure 1. ANOVA results of transparency values for matrices of poly(lactide-co-glycolide) (PLG), poly(lactideco-caprolactone) (PLC), poly-E-caprolactone (PCL), and amniotic membrane (AM); control is quartz glass KU-1

Table. Main mechanical characteristics of the studied synthetic matrices and amniotic membrane

\begin{tabular}{|l|c|c|c|}
\hline Specimens & $\begin{array}{c}\text { Strength } \\
\sigma_{\mathrm{p}}, \mathrm{MPa}\end{array}$ & $\begin{array}{c}\text { Relative } \\
\text { elongation at } \\
\text { break } \varepsilon_{\mathrm{p}}, \%\end{array}$ & $\begin{array}{c}\text { Elastic } \\
\text { modulus E, } \\
\mathrm{MPa}\end{array}$ \\
\hline PLC $5 \mu \mathrm{m}$ & $27 \pm 5$ & $3.5 \pm 1.0$ & $1652 \pm 300$ \\
\hline PLC $10 \mu \mathrm{m}$ & $29 \pm 3$ & $4.3 \pm 2.0$ & $2190 \pm 220$ \\
\hline PLC $15 \mu \mathrm{m}$ & $33 \pm 5$ & $4.7 \pm 0.8$ & $2186 \pm 575$ \\
\hline PLG $5 \mu \mathrm{m}$ & $40 \pm 9$ & $3.2 \pm 0.6$ & $2275 \pm 550$ \\
\hline PLG $10 \mu \mathrm{m}$ & $50 \pm 6$ & $3.2 \pm 1.2$ & $2730 \pm 230$ \\
\hline PLG $15 \mu \mathrm{m}$ & $51 \pm 4$ & $3.6 \pm 1.0$ & $2578 \pm 330$ \\
\hline PCL $5 \mu \mathrm{m}$ & $13 \pm 3$ & $45.0 \pm 29.0$ & $309 \pm 67$ \\
\hline PCL $10 \mu \mathrm{m}$ & $9 \pm 2$ & $30.0 \pm 9.0$ & $349 \pm 54$ \\
\hline PCL $15 \mu \mathrm{m}$ & $14 \pm 1$ & $71.0 \pm 38.0$ & $349 \pm 40$ \\
\hline Amniotic & $0.8 \pm 0.2$ & $50.0 \pm 11.0$ & $0.19 \pm 0.07$ \\
\hline membrane & & & \\
\hline
\end{tabular}




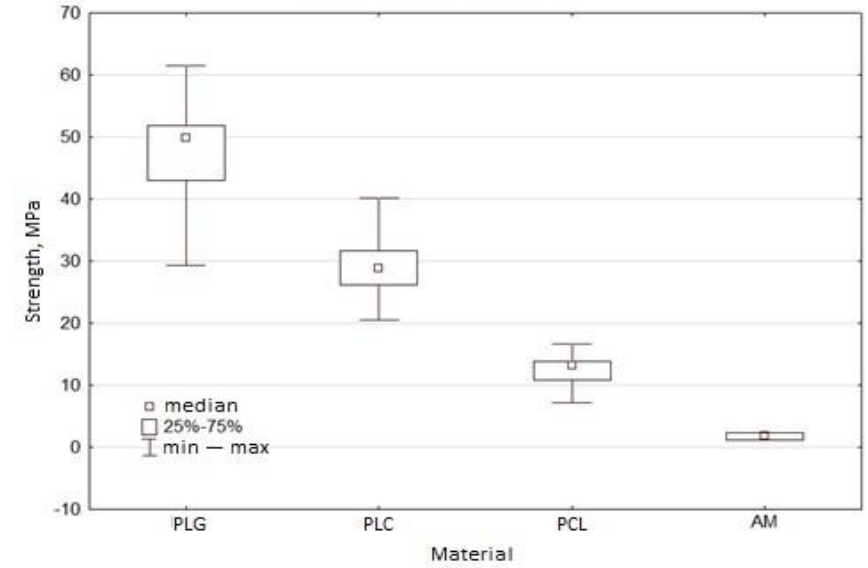

Figure 2. Results of nonparametric Kruskal-Wallis analysis for the strength of matrices made of poly(lactide-coglycolide) (PLG), poly(lactide-co-caprolactone) (PLC), polyE-caprolactone (PCL), and amniotic membrane (AM)

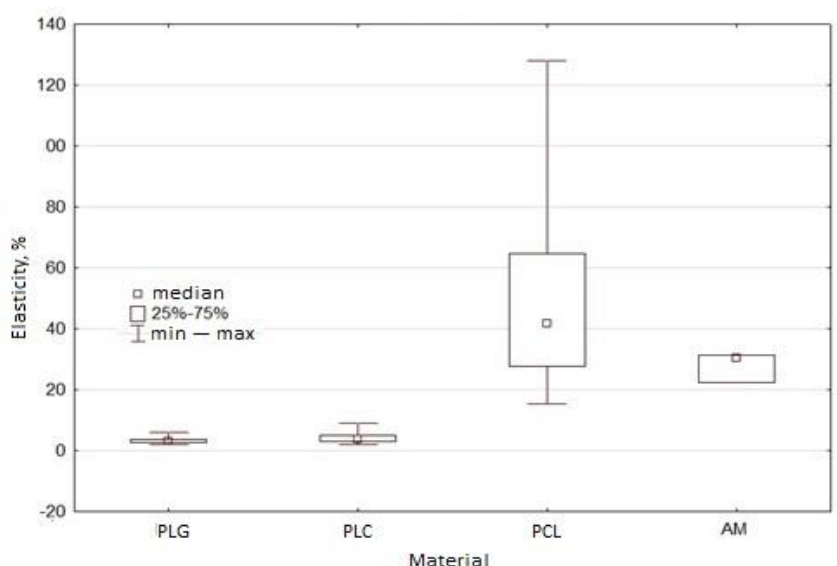

Figure 3. Results of nonparametric Kruskal-Wallis analysis for the elasticity (relative elongation at break) of matrices made of poly(lactide-co-glycolide) (PLG), poly(lactide-cocaprolactone) (PLC), poly-E-caprolactone (PCL), and amniotic membrane (AM)

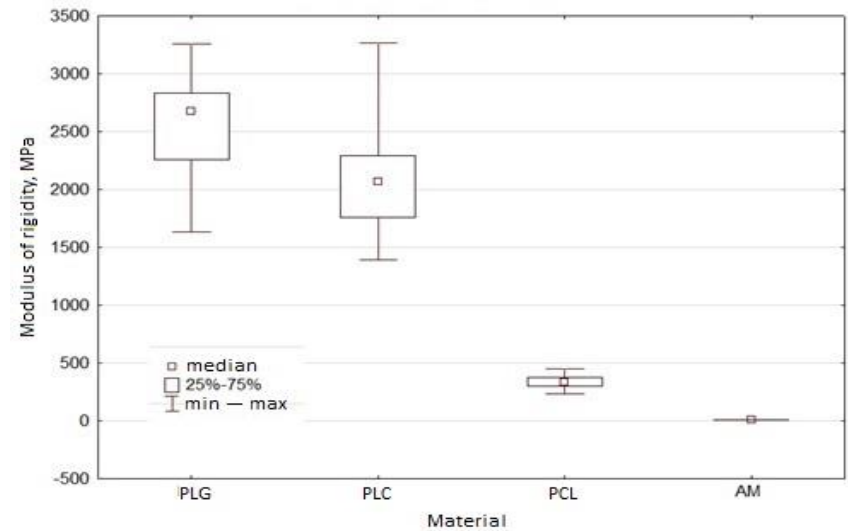

Figure 4. Results of nonparametric Kruskal-Wallis analysis for the elastic modulus of matrices made of poly(lactide-coglycolide) (PLG), poly(lactide-co-caprolactone) (PLC), polyE-caprolactone (PCL), and amniotic membrane (AM)

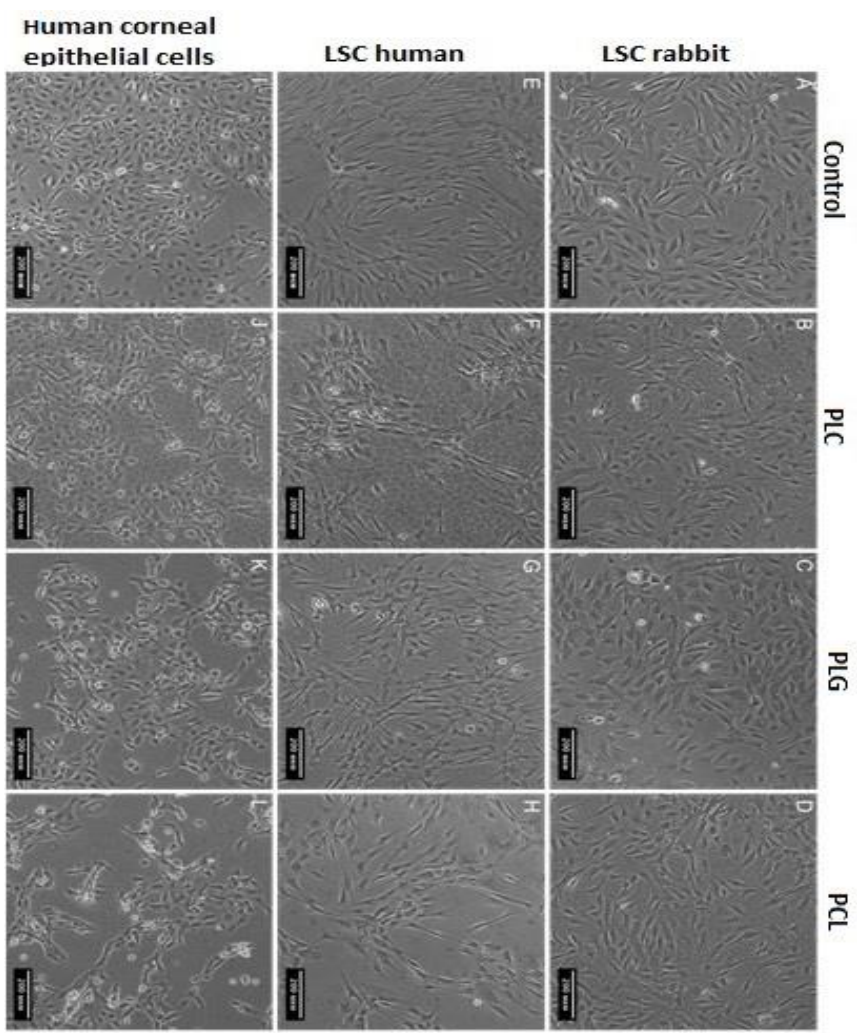

Figure 5. Cultivating rabbit LSC (A-D); Human LSC (E-H); HCE cells (I-L) on the surface of matrices based on PLC, PLG, PCL and cell culture plastic (control); morphology of rabbit and human LSC and human HCE cells on day 2; scale bar $200 \mu \mathrm{m}$

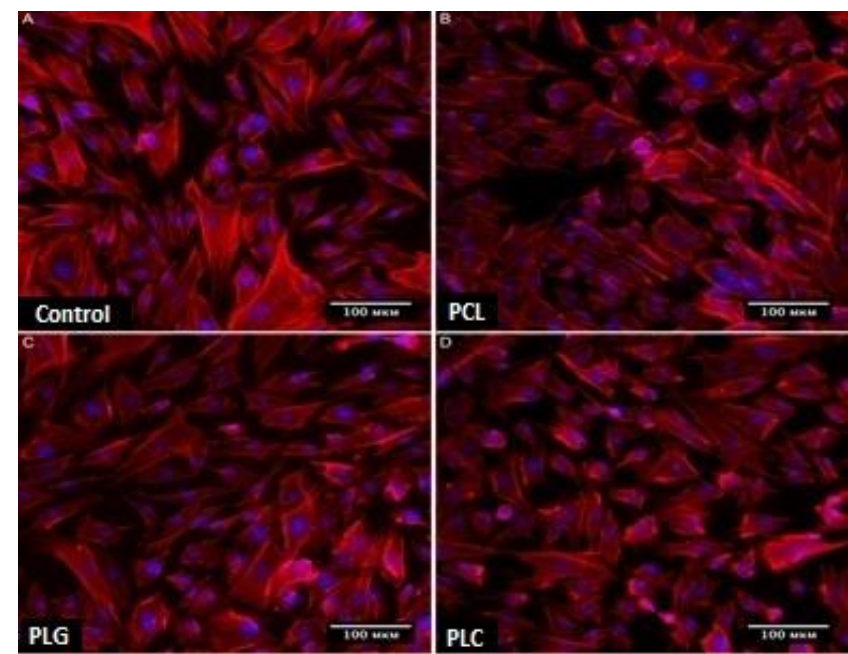

Figure 6. Rabbit LSC spread out on cell culture plastic as the control (A), synthetic matrices made of PCL (B), PLG (C) and PLC (D); the actin cytoskeleton is stained with rhodamine-phalloidin (red), the nuclei are stained with DAPI (blue); scale bar $100 \mu \mathrm{m}$ 
Using the colorimetric test with gentian violet, it was established that in the control, regardless of the cell type, a more active proliferation of all cell types was observed $(p<0.001)$. However, when cultured on matrices, the cells retained the ability to divide. On the 2nd day of cultivation, there was a sufficient number of viable cells on the matrices to maintain the population. For rabbit LSC and HCE cells, the number of cells on all types of matrices was approximately the same ( $p>0.05)$. However, for human LSC, the PLG matrix was evaluated as the top choice.

In the course of analyzing the organization of the actin cytoskeleton of rabbit LSCs spread out on matrices (Figure 6), it was shown that the cells in all experimental samples were well spread out, and had a characteristic shape and size for this type. Actin is mainly concentrated in filament bundles. Intercellular contacts were practically absent both in the control and in the experimental variants. In all cases, mitotic activity was observed.

Collagen hydrogel was used to assess the rate of LSC migration from the matrix surface. In vitro, it has been shown that human LSC begin migrating from the surface of the matrices to the adjacent collagen hydrogel within 24 hours. However, the migration rate was rather low; the highest migration activity was observed in the area of contact between the edge of the matrix and the collagen gel. It was revealed that cells migrate not only to the surface of the hydrogel, but also into it. By the end of the 4th week of cultivation, a large number of cells were observed on the surface and inside the hydrogel, as well as on the surface of the matrix. The rate and activity of LSC migration from different types of matrices was comparable to the control.

As a result of observing the biodegradation of matrices based on PLG on the 3rd day, no signs of material degradation were revealed in any case. On the 1oth day, thinning edges of the matrices in the area of suturing was noted only on specimens $5 \mu \mathrm{m}$ thick. On the 21st day, separate areas of material destruction appeared on matrices 5 $\mu \mathrm{m}$ thick, and material defects in the area of seams appeared on matrices with a thickness of $10 \mu \mathrm{m}$; there were no changes in the integrity of the material on the $15 \mu \mathrm{m}$ matrices. On the 3oth day, there was a complete defect in the material in the optical zone of matrices with a thickness of $5 \mu \mathrm{m}$. Some degraded regions appeared on matrices $10 \mu \mathrm{m}$ thick. The 15 $\mu \mathrm{m}$ matrices underwent just initial changes in integrity in the suture area.

On the 3rd day, the first signs of degradation appeared only on PLC-based matrices $5 \mu \mathrm{m}$ thick. On the 1oth day, areas of destruction appeared on $5 \mu \mathrm{m}$ thick matrices; the initial signs of material degradation in the area of the seams were noted on specimens $10 \mu \mathrm{m}$ thick. On day 21, almost complete destruction of $5 \mu \mathrm{m}$ thick matrices was observed. On matrices with a thickness of $10 \mu \mathrm{m}$ and $15 \mu \mathrm{m}$, we noticed the appearance of destruction regions and signs of initial degradation, respectively. On the 3oth day, specimens $5 \mu \mathrm{m}$ thick completely degraded. Specimens of matrices with a thickness of $10 \mu \mathrm{m}$ degraded by over 50\%. Specimens $15 \mu \mathrm{m}$ thick had changes in the form of island-shaped destruction regions.

As a result of observing biodegradation of PCL-based matrices on the 3rd, 10th and 21st days, no signs of material degradation were revealed in any subgroup. On the 3oth day, the we observed an appearance of thinning edges of the matrices in the area of suturing - but only on specimens 5 $\mu \mathrm{m}$ thick.

\section{Discussion}

One of important optical properties of the material, used as a carrier for LSC transplantation onto the cornea is its high transparency. This property allows improving the visualization when observing the processes of cell cultivation on the surface of the carrier in vitro. Besides, the increased transparency facilitates conducting a more detailed assessment of the ocular surface condition after transplanting a carrier with LSC on it, in order to assess the occurrence of inflammatory changes, the transparency of the cornea, and the degree of its vascularization [14].

Our results concerning the transparency implied that the best matrices in this respect for use as carriers were the matrices made of synthetic materials PLG and PLC.

In terms of its mechanical properties, AM is an entirely suitable material for use in ophthalmic surgery. According to the results of our studies, matrices made of PCL and PLC with a thickness of $5^{-15} \mu \mathrm{m}$ had the closest to AM values of strength, relative elongation at break and elastic modulus.

When comparing the mechanical properties of PLG and PLC matrices, the matrix made of PLC had the closest to AM values.

Evaluation of the in vitro biocompatibility of synthetic polymer matrices for LSC and HCE, using cell testing systems, showed that it is possible to maintain cell cultures in vitro on the surface of the matrices. The cells retain their typical morphology and spread well. However, the adhesion and proliferation of both LSC and HCE on the matrix surface in our experiments was lower than in the control. According to the results of our in vitro studies, it is impossible to unequivocally establish the matrix that is most suitable for all required criteria for culturing eye tissue cells. For example, rabbit LSC adhere, proliferate, and migrate about the same in all variants of the matrices. For LSC and epithelial cells of the human cornea, the matrix made of PLG was the most preferable, since the distribution of cells on it was more uniform; although the results of colorimetric analysis

Additionally, it is worth noting that matrices, populated with cells, may act as 'transmitters', delivering the cells to the damaged area when transplanted onto the wound surface. The in vitro collagen hydrogel model suggests that it takes at least 3-4 weeks to provide the damaged area with sufficient number of cells. However, the in vitro model does not fully correspond to the conditions, in which cells find themselves after transplantation - hence, further studies, using in vivo models, are needed to determine more accurate timing.

When comparing the duration of biodegradation, it was revealed that PLC matrices $(5 \mu \mathrm{m})$ began to degrade noticeably already on the 1oth day, whereas on the specimens of PLG matrices $(5 \mu \mathrm{m})$, reliable signs of degradation were observed much later (on the 21st day). The first signs of degradation of PCL matrices were noted on the 3oth day, and only in the subgroup with a material thickness of $5 \mu \mathrm{m}$. Complete biodegradation of $5 \mu \mathrm{m}$ thick PLC matrices took no more than 30 days. Consequently, PLC matrix biodegradation happened faster than in case of PLG, and in terms of its timing, it was comparable to the timing of AM lysis on the corneal surface [15].

\section{Conclusion}

Based on the study of transparency, mechanical properties, biocompatibility and duration of biodegradation, the matrix carrier of LSCs, made of $5 \mu \mathrm{m}$ thick poly-L-lactide- 
caprolactone, was identified as the most consistent with the requirements, and in terms of strength, even superior to the amniotic membrane. When planning an experimental operation of limbal transplantation, this variant of the carrier may be used as a carrier of cultured LSCs.

\section{Conflict of interest}

The authors declare no conflict of interest.

\section{References}

1. Global Initiative for the Elimination of Avoidable Blindness Geneva: World Health Organization, 1997; 48.

2. Pascolini D. Global estimates of visual impairment: 2010. $\mathrm{Br} J$ Ophthalmol 2012; 96 (5): 614-8. https://doi.org/10.1136/bjophthalmol-2011-300539

3. Lim AS. Mass blindness has shifted from infection (onchocerciasis, trachoma, corneal ulcers) to cataract. $\begin{array}{lllll}\text { Ophthalmologica } & 1997 ; & 211 & \text { (4): } & 270 .\end{array}$ https://doi.org/10.1159/000310806.

4. Libman ES, Shakhova EV. Blindness and visual impairment in the population of Russia. In: VIII Congress of Russian Ophthalmologists. Moscow, 2005; p. 78-9. (in Russian).

5. Kasparov AA. Treatment of the most important cornea diseases. In: VIII Congress of Russian Ophthalmologists. Moscow, 2005; p. 450-1. (in Russian).

6. Maychuk YuF. Major trends in epidemiology and treatment of eye infections. In: VIII Congress of Russian Ophthalmologists. Moscow, 2005; p. 92-3. (in Russian).

7. Slonimsky AYu. Opportunities for penetrating keratoplasty at various pathologies of the anterior eye segment. Clinical Ophthalmology 2001; (3): 102-5. (in Russian). https://doi.org/10.1016/j.ophtha.2008.12.043

8. Reinhard T. Corneal Disease: Recent Developments in Diagnosis and Therapy. Springer-Verlag-Berlin. Heidelberg 2013; 121.

9. Chernysh VF, Boyko EV. Eye Burns: State of the Problem and New Approaches. Moscow: GEOTAR-Media 2017; 184. (in Russian).

10. Holland EJ, Schwartz GS. The evolution of epithelial transplantation for severe ocular surface disease and a proposed classification system. Cornea 1996; 15: 549-56. https://pubmed.ncbi.nlm.nih.gov/8899265/

11. Grueterich M, Espana EM, Tseng SC. Ex vivo expansion of limbal epithelial stem cells: amniotic membrane serving as a stem cell niche. Surv Ophthalmol 2003; 4 (6): 631-46. https://doi.org/10.1016/j.survophthal.2003.08.003

12. Pellegrini G, Traverso CE, Franzi AT, et al. Long-term restoration of damaged corneal surfaces with autologous cultivated corneal epithelium. Lancet 1997; 349 (9057): 990-3. https://doi.org/10.1016/So140-6736(96)11188-o

13. Sefat F, et al. Production, sterilization and storage of biodegradable electrospun PLGA membranes for delivery of limbal stem cells of the cornea. Procedia Engineering 2013; 59: 101-16. https://doi.org/10.1016/j.proeng.2013.05.099

14. Kulikov AN, Churashov SV, Chernysh VF, et al. Current approaches to the problem of selecting carrier for cultivating limbal stem cells for treating limbal stem cell deficiency. Oftalmologicheskie vedomosti 2018; 11 (2): 48-56. (in Russian). https://doi.org/10.17816/OV11248-56

15. Neroev VV, Gundorova RA, Makarov PV, et al. Eye Burns: a Guide for Doctors. Moscow: GOTAR-Media, 2013; 224. (in Russian).

\section{Authors:}

Vadim V. Karpovich - Clinical Resident, Department of Ophthalmology, S.M. Kirov Military Medical Academy, St. Petersburg, Russia;

Alexey N. Kulikov - DSc, Associate Professor, Head of the Department of Ophthalmology, S.M. Kirov Military Medical Academy, St. Petersburg, Russia;

Sergey V. Churashov - DSc, Professor, Department of Ophthalmology, S.M. Kirov Military Medical Academy, St. Petersburg, Russia;

Valery F. Chernysh - PhD, Assistant Professor, Department of Ophthalmology, S.M. Kirov Military Medical Academy, St. Petersburg, Russia;

Stepan G. Grigoriev - DSc, Professor, Senior Research Scientist, Scientific Research Center, S.M. Kirov Military Medical Academy, St. Petersburg, Russia;

Miralda I. Blinova - PhD, Assistant Professor, Head of the Laboratory of Cell Biotechnology, Institute of Cytology, Russian Academy of Sciences, St. Petersburg, Russia;

Yulia A. Nashchekina - PhD, Senior Research Scientist, Center for Cell Technology, Institute of Cytology, Russian Academy of Sciences, St. Petersburg, Russia;

Olga I. Alexandrova - Research Scientist, Center for Cell Technology, Institute of Cytology, Russian Academy of Sciences, St. Petersburg, Russia;

Yulia I. Khorolskaya - Graduate Student, Center for Cell Technology, Institute of Cytology, Russian Academy of Sciences, St. Petersburg, Russia;

Pavel O. Nikonov - Senior Laboratory Technician, Center for Cell Technology, Institute of Cytology, Russian Academy of Sciences, St. Petersburg, Russia;

Ekaterina S. Tsobkallo - DSc, Professor, Chair of the Department of Materials Science Engineering and Metrology, Saint Petersburg State University of Industrial Technology and Design, St. Petersburg, Russia;

Olga A. Moskalyuk - PhD, Senior Lecturer, Department of Materials Science Engineering and Metrology, Saint Petersburg State University of Industrial Technology and Design, St. Petersburg, Russia;

Alexander S. Melnikov - PhD, Research Scientist, Scientific Research Complex 'NanoBio', Peter the Great St. Petersburg Polytechnic University, St. Petersburg, Russia;

Pavel Yu. Serdobintsev - PhD, Research Scientist, Scientific Research Complex 'NanoBio', Peter the Great St. Petersburg Polytechnic University, St. Petersburg, Russia;

Tatiana V. Mashel - Undergraduate Student, Peter the Great St Petersburg Polytechnic University, St. Petersburg, Russia;

Galina A. Pisugina - Undergraduate Student, St. Petersburg State University, St. Petersburg, Russia;

Daria A. Perepletchikova - Undergraduate Student, Peter the Great St. Petersburg Polytechnic University, St. Petersburg, Russia;

Dmitry A. Khoroshikh - Cadet, S.M. Kirov Military Medical Academy, St. Petersburg, Russia. 